\title{
Alan Ayckbourn (2013): Theaterhandwerk. 101 selbstverständliche Regeln für das Schreiben und Inszenieren, 4. Auflage.
}

Berlin: Alexander Verlag, 187 Seiten (ISBN 3-89581-144-9)

\author{
Nina Hasenzagl
}

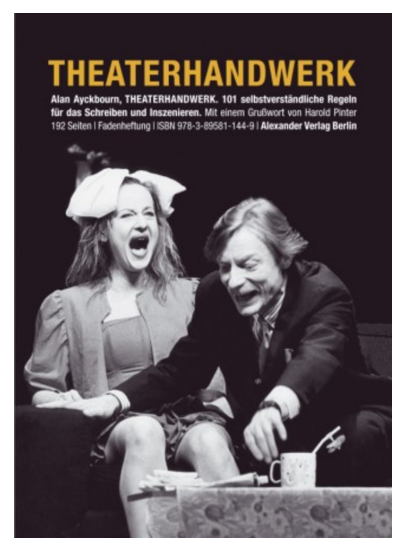

Abbildung 1: //www.alexander-verlag.com/programm/titel/84-Theaterhandwerk.html

Obwohl ich selbst noch nie ein Stück von Ayckbourn gesehen, geschweige denn gelesen habe, schaffte er es mit seiner aufblühenden und lebendigen Schreibweise, mich in seine Geschichten und Denkweisen zu entführen, sodass ich äußerst gewillt bin, mir demnächst eines seiner Theaterstücke zu Gemüte zu führen. Doch vorerst, worum es in diesem Buch überhaupt geht:

Es trägt den Titel Theaterhandwerk, womit einige Themenfelder in Frage kommen könnten. Der Untertitel verrät schon eher, in welche Richtung Ayckbourn lenken will. Verhalten gibt sich allerdings das Inhaltsverzeichnis. Nur einige Schlagwörter deuten darauf hin, was jedes einzelne Kapitel mit sich bringt. Danach stellt der Autor kurz und charmant seinen eigenen Bezug zum Theater vor, welcher vom gescheiterten Schauspieler, über diverse Tätigkeiten als Bühnenarbeiter bis hin zum gefeierten und einem der gegenwärtig meistgespieltesten Theaterautoren führt. Mit Lorbeeren schmückt er sich dennoch nicht; seine Auszeichnung als „Order of the British Empire“ durch die Queen of England wird einzig auf der Buchumschlagsrückseite erwähnt.

Die Kapitel Schreiben und Inszenieren bilden das Grundgerüst des Buches und geben eine klare Struktur vor. Gespickt werden diese Hauptpfeiler durch sogenannte "selbstverständliche Regeln", nämlich erprobte Handlungsanweisungen seitens des Autors. Dabei entsteht der Eindruck, er habe seine Stücke 
schon hundertmal selbst aufgeführt und zu jedem einen immensen emotionalen Erfahrungsreichtum angesammelt, so lebendig werden sie - in Auszügen wiedergegeben. Gerade diese Auszüge sind es, an denen er geschickt erläutert, was das wahre „Handwerk“ ist, das er den Leserinnen und Lesern dieses Buches weitergeben möchte.

Fast schon lächerlich erscheint der Tipp, kein Stück anzufangen, wenn keine Idee vorhanden ist - und trotzdem belegt Ayckbourn diesen simplen Ansatz eindringlich und nachvollziehbar. Es sind diese kleinen Tricks, die Ayckbourn aus seiner Schreiberfahrung schöpft und weitergeben will, kleine Fehler, auf die er hinweist und die viele Theaterautorinnen und -autoren, unachtsam im Schreibprozess, tatsächlich machen. Zu keiner Zeit sieht man Ayckbourn mit erhobenem Finger vor sich stehen, eher noch kommt das Bild in den Sinn, man sitze in einem seiner früheren Seminare an der Oxford University.

Liegt die Empfindung nahe, der erste Teil des Buches sei schon ziemlich umfangreich, so wird man im zweiten Teil, Inszenieren, förmlich mit Ratschlägen überhäuft. Angefangen bei den Aufgaben einer Regisseurin/eines Regisseurs, über weitere Berufszweige im kommerziellen Bühnenbetrieb, kommen selbst Tipps zu Tätigkeiten von und mit Schauspielerinnen und Schauspielern bis hin zu jeglicher Art von Proben nicht zu kurz. Die Unterkapitel Voraufführungen, Premiere und Danach bilden den Abschluss des Buches und zeigen ganz klar, der Prozess eines Theaterstückes ist um ein Vielfaches länger als die eigentliche Spielzeit. Autoren und Regisseure leben für diesen Prozess und es lässt sich kaum treffender sagen als mit den Worten Ayckbourns:

Denn das Wichtige ist, dass Sie [als Regisseur] und die Schauspieler wissen, wie wichtig Ihre Arbeit für das Ganze gewesen ist. (180)

Oft erwähnt und dennoch kritisch betrachtet der Autor das Metier der Regieführung. Es liegt ihm viel daran, dass diese wichtige Tätigkeit weder über- noch unterschätzt wird und zur gleichen Aufmerksamkeit gelangt wie das Wirken der Schauspielerinnen und Schauspieler.

Mit diesem Buch gibt Ayckbourn selbst Theaterunerfahrenen einen klaren, durchdachten Überblick in die Entstehung und Inszenierung einer Bühnenproduktion. Die darin empfohlenen „selbstverständlichen Regeln“ erheitern die Leserin/den Leser stets und sind keinesfalls als starre Manifeste zu verstehen. Die Leichtigkeit dieser Lektüre beflügelt förmlich zu neuen Ideen und betrachtet bisher vielleicht unbeachtete Elemente aus einem neuen Blickwinkel. 